[Aus dem hygienischen Institut der Universität Berlin.]

\title{
Die Einwirkungen des lebenden Froschkörpers auf den Miizbrandbacillus:
}

Von

Dr. Johannes Petruschky.

(Hierzu Taf. I.)

Im Band XIV, Seite 465 von ,Virch ow's Archiv" bespricht Metschnikoff die im letzten Jahre erschienenen Veröffentlichungen, welche sich mit seiner „Phugocyten-Theorie" beschäftigen. Hierbei unterwirft er ausser den interessanten Arbeiten aus dem Breslauer hygienischen Institut (von Flügge, Bitter, Nuttall etc.) ${ }^{1}$ auch meine erste unter Baumgarten in Königsberg ausgeführte Arbeit, welche diesen Gegenstand behandelt, ${ }^{2}$ einer ziemlich ausführlichen kritischen Besprechung, welche ibre Angriffe nicht gegen die Resultate meiner Untersuchungen, wohl aber gegen deren Deutung und gegen ihre Beweiskraft gegenüber seiner (Metschnik off's) Theorie richtet. Wiewohl ich nun schon auf Grund meiner ersten Untersuchungen Metschnikoff's Einwände zurückweisen zu können glaube, habe ich im Berliner hygienischen Institut noch weitere Versuche allgestellt, um die Einwürfe Metschnikoff's möglichst direct zu widerlegen. Auch ist mir durch die Güte des Herrn Dr. Fränkel die photographische Wiedergabe einiger charakteristischer Präparate ermöglicht worden.

${ }^{1}$ Flügge, Studien über die Abschwächung virulenter Bacterien und die erworbene Immunität. Diese Zeitschrift. Bd. IV S. 208.

* Petruschky, Ueber die Inmunität des Frosches gegen Milzbrand. Zieglel und Nauwerck. Bd. III. S. 359. 
I.

Zunächst wendet sich Metschnikoff gegen die von mir angeführte Beobachtung, dass bei massenhaften Injectionen von Milzbrandbacillen, welche man aus dem verflüssigten Theil von acht- bis vierzehntägigen Gelatineculturen gewinnt, ausser der Aufnahme der Bacillen durch Leukocyten auch eine Degeneration frei in der Lymphflüssigkeit liegender Bacillenfäden zu beobachten ist. Er führt nämlich aus, dass in einer Gelatinecultur ausser virulenten Bacillen auch abgestorbene und im $A b$ sterben begriffene Milzbrandfäden vorhanden seien, und dass daher die Deutung der Resultate meiner ersten Versuchsreihe in der Weise denkbar wäre, dass gerade alle virulenten Bacillen von Leukocyten gefressen würden, während die in der freien Lymphflüssigkeit beobachtete Bacillendegeneration sich nur auf schon abgestorbene Milzbrandfäden beziehe. Diese Auslegung wird dem Unbefangenen schon deshalb ziemlich gezwungen erscheinen, weil nach Massgabe aller seitherigen Untersuchungen über die Phagocytenthätigkeit so viel schon feststeht, dass die Leukocyten abgestorbene oder abgeschwächte Bacillen zweifellos gern aufnehmen, während sie gegen die unzweifelhaft virulenten und lebenskräftigen Bacillen - bei empfänglichen Thieren, beim erwärmten Frosch - eine grosse Scheu an den Tag zu legen scheinen. Ueberdies kann ich gegen Metschnikoff's Auslegung der Art, wie ich meine Versuche angestellt habe, Folgendes geltend machen. Die Virulenz der von mir benutzten Culturen wurde an Mäusen erwiesen, indem ihnen eine einzige Platinöse mit Culturmaterial an der Schwanzwurzel unter die Haut gebracht wurde; sie starben regelmässig nach 36 Stunden. Den Fröschen dagegen wurde $1 / 2$ bis $1 \mathrm{~cm}$ desselben Culturmaterials in den Rückenlymphsack injicirt, ohne dass von den 12 so behandelten Thieren ein einziges $\mathrm{zu}$ Grunde ging. Die aus dęm Rückenlymphsack der betreffenden Frösche entnommene Lymphe zeigte sich in den ersten Stunden nach der Injection dicht gefüllt mit Bacillenfäden, welche durchweg glatt und gesund aussahen. Dieses Aussehen änderte sich erst im Laufe des zweiten Tages, und die Degenerationserscheinungen griffen dann so constant und gesetzmässig um sich, dass es sich um zufällige Befunde nicht handeln konnte. Dass die Widerstandsfähigkeit gegen die schädigenden Einflüsse des Froschkörpers nicht bei allen Bacillen die gleiche war, ist auch von mir selbst hervorgehoben worden; doch wird durch diese Thatsache nicht ausgeschlossen sein, dass auch der im Froschkörper am schnellsten absterbende Bacillenfaden in einem empfänglichen Thiere noch gediehen wäre und den Tod des Thieres hätte bewirken können. Schliesslich ist hervorzuheben, dass die von mir benutzten Bacillen nicht nur Mäuse, sondern bei den geeigneten 
Temperaturen auch Frösche zu inficiren und zu tödten vermochten unter colossaler Wucherung in den Organen, namentlich den Lungen.

$\mathrm{Um}$ indessen Metschnik off's Einwendungen gegen das benutzte Impfmaterial ganz den Boden zu entziehen, habe ich gemäss seinem eigenen Vorschlage neuerdings auch das Blut an Milzbrand gestorbener Thiere - Mäuse und Meerschweinchen - zur Beschickung der Frösche benutat. Liess ich die mit Milzbrandblut geimpften Frösche bei der gewöhnlichen Zimmertemperatur von 16 bis $22^{\circ} \mathrm{C}$. stehen, so war das erste, was sich auf's Deutlichste feststellen liess, dass keines der vielen kurzen Stäbchen im Froschkörper auswuchs, wiewohl 14 Tage, ja drei Wochen lang ausser reichlicher Phagocytose auch stets eine reiche Menge freigebliebener, Bacillen in den entnommenen Lymphproben regelmässig zu beobachten war. Die morphologisch nachweisbare Degeneration der Bacillen scheint indessen in diesen Fällen erst weit später einzutreten, als bei Benutzung von Culturbacillen; ich vermochte eine solche erst in der zweiten Woche nach der Impfung, und zwar nicht minder an freiliegenden, als an eingeschlossenen Bacillen zu beobachten. 14 Tage nach der Impfung enthielt die Froschlymphe in jedem entnommenen Tropfen eine Reihe in Degeneration begriffener Bacillen, ausserdem aber auch noch eine beträchtliche Anzahl ganz glatt und anscheinend normal aussehender. Trotzdem verlief die Impfung einer Maus, welche mit dem gesammten Inhalt des Lymphsacks, einschliesslich eines dort entstandenen, sehr bacillenhaltigen, gallertigen Exsudates ausgeführt wurde, ganz negativ. Die von einem anderen Frosche drei Wochen nach seiner Beschickung an einer Maus ausgeführte Impfung führte hingegen noch zum Tode der Maus (innerhalb drei Tagen) an Milzbrand. Es scheint daher auch die Widerstandsfähigkeit der im Milzbrandblut enthaltenen Bacillen gegen die feindlichen Einflüsse des Froschkörpers eine sehr ungleichmässige zu sein. Diese Ungleichmässigkeit der Resistenz, welche demnach nicht bloss den Culturbacillen eigen ist, macht es schwer, bei den vorliegenden Untersuchungen den Untergang der Bacillen im Froschkörper durch Thierimpfungen nachzuweisen und bedingt die Verlegung des Hauptgewichtes auf die mikroskopischen Befunde.

Auf Veranlassung des Herrn Geheimrath Koch setzte ich Frösche, welche mit Blut, bezw. mit saftreichen Organstücken an Milzbrand gestorbener Thiere beschickt waren, nicht der gewöhnlichen Zimmertemperatur, auch nicht der Brütschrankwärme aus, sondern stellte dieselben in die unmittelbare Nähe des Ofens, wo die Temperatur am Tage gewöhnlich bis 26 und $27^{\circ} \mathrm{C}$, hin und wieder aber auch bis $31^{\circ} \mathrm{C}$. stieg, sodass den Bacillen hier wenigstens an einem Theil des Tages eine Wärme gewährt wurde, welche ihr Auswachsen auch im Froschkörper gestattete. 
In der That war auch in den entnommenen Lymphtropfen das Wachsthum zahlreicher Bacillen zu kürzeren oder längeren Fäden zu constatiren, und zwar hatte dasselbe nicht nur in der freien Lymphe, sondern augenscheinlich auch in Leukocyten stattgefunden, eine Beobachtung, welche bereits ron $\mathrm{Koch}$ im zweiten Band der Beiträge zur Biologie der Pflanzen (herausgegeben von F. Cohn) mitgetheilt wurde. Es fanden sich nämlich bei den betreffenden Fröschen in einer Anzahl von Leukocyten spiralig gewundene, oft nach Art eines Schiffstaues aufgewickelte Fäden vor, die sich in ihrer Gestalt wesentlich von den Zusammenkrümmungen und Kranzformen unterscheiden, welche aufgenommene Bacillenfäden in den Leukocyten secundär anzunehmen pflegen. Diese Erscheinung kann in Uebereinstimmung mit dem ganzen Bilde eines allgemeinen Wachsthums beginns der eingeführten Bacillen nur aufgefasst werden als ein Auswachsen solcher Bacillen, die bereits ron Leukocyten aufgenommen worden waren.

Geht nun aus dieser Beobachtung hervor, dass die Leukocyten nicht einmal ein Wachsthumshinderniss für die von ihnen aufgenommenen Bacillen sind, so zeigt andererseits eine zweite bei denselben Versuchen sich darstellende Erscheinung wieder auf's Deutlichste ein Absterben von Bacillen in der freien Lymphflüssigkeit. Während nämlich, wie bereits erwähnt, die kurzen Bacillen des Milzbrandblutes erst sehr spät morphologische Veränderungen im Frosche erfahren, zeigen die Fäden, welche im Inneren der in der Nähe des Ofens gehaltenen Frōsche ausgewachsen sind, grossentheils schon am zweiten Tage nach der Beschickung ein Bild, wie es in Fig. III eine aus den betreffenden, mit Nethylenblau gefärbten und - wie immer in diesen Versuchen - ohne Erhitzung des Deckglases hergestellten ${ }^{1}$ Präparaten beliebig herausgegriffene Stelle charakteristiseh wiedergiebt.

Die Bacillen zeigen eine allgemeine Anschwellung, welche ganz besonders an den Enden der Einzelglieder eines Fadens hervortritt, während die Mitte der Glieder relativ schmächtiger und wie angefressen erscheint, sodass ein ganzer Faden das Aussehen eines Bambusstabes oder eines der Gräten entblössten Fischrückgrates erhält. Ferner wird bei diesen Fäden oft, namentlich bei Fuchsinfärbung, ein axialer Inhalt von einer peripheren, gequollen erscheinenden Hülle deutlich unterscheidbar. Es unterliegt wohl keinem Zweifel, dass derartig veränderte Bacillen nicht mehr als normale und gesunde anzusprechen sind. Die pathologische Veränderung derselben kann aber auf die Leukocyten nicht zurückgeführt werden, da diese Fäden überwiegend in der freien Lymphflüssigkeit sich

1 Petruschky, a. a. O. S. 364. Anmerkung 1. 
Enwirkungten D. Lebend. Froschrörpers a. D. Muzbrandbacillus. 79

finden und grösstentheils von gestreckter Gestalt und einer so bedeutenden Länge sind, dass keinesfalls angenommen werden kann, dieselben seien bei der Präparation aus Leukocyten herausgefallen.

II.

Die in der dritten Versuchsreihe meiner ersten Arbeit angeführten Versuche, bestehend in Beschickung der Frösche mit Sporen, welche aus Kartoffelculturen durch zweistündiges Erhitzen in destillirtem Wasser auf $62^{\circ} \mathrm{C}$. isolirt worden waren, hatten das Resultat ergeben, dass die Sporen im Froschkörper bei Zimmertemperatur gar nicht, bei 28 bis $30^{\circ} \mathrm{C}$. dagegen reichlich auswuchsen und dann in der freien Lymphflüssigkeit degenerirten; bei 35 bis $37^{\circ} \mathrm{C}$. führten sie unter sebr reichlichem Wachsthum zum Tode der beschickten Frösche. Auch diese Versuche will Metschnikoff nicht gelten lassen, weil nach seinem Erachten durch das Erhitzen die Sporen eine Abschwächung erlitten haben könnten, welche ein Wuchern ihrer Schösslinge ohne Schaden des Frosches ermögliche.

Abgesehen davon, dass eine derartige Abschwächung virulenter Sporen durch zweistündiges Erhitzen auf $62^{\circ} \mathrm{C}$. sonst von Niemand benbachtet worden ist, habe ich ausdrücklich hervorgehoben, dass dieselben Sporen bei 35 bis $37^{\circ} \mathrm{C}$. die Frösche tödteten. Ausserdem ist die Wachsthumsfübigkeit und die Virulenz der Sporen nach der Erhitzung durch Culturund Impfversuche selbstverständlich geprüft worden. Die Abbildungen I und II werden die beobachteten Erscheinungen besser veranschaulichen, als eine Beschreibung es kann. Fig. I stellt Milzbrandfäden dar, welche bei 35 bis $37^{\circ} \mathrm{C}$. im Froschlymphsack aus Sporen ausgewachsen sind. Fig. II einen solchen, der bei 28 bis $30^{\circ}$ C. gewachsen und ohne Phagocytose degenerirt ist.

Neuerdings habe ich nun die Versuche mit sporenhaltigen Seidenfäden wiederholt, welche ich von Herrn Dr. C. Fränkel erhielt und deren maximale Virulenz wiederholt erprobt wurde. Dieselben verwendete ich, indem ich theils die Seidenfäden selbst, theils Aufschwemmungen der in ihnen enthaltenen Sporen in sterilisirtem Wasser in den Froschlymphsack einführte. Die Resultate entsprachen vollständig den früheren Beobachtungen. Die Sporen wuchsen bei Zimmertemperatur gar nicht aus. Bei mässig erhöhter Temperatur fand reichliches Wachsthum und reichliche Degeneration in der freien Lymphe statt (mässige Phagocytose) bei noch weiter erhöhter Temperatur erkrankte und starb der Frosch an Milzbrand.

Nicht unerwähnt will ich lassen, dass bei den neueren Versuchen der Tod eines Frosches allerdings schon bei $31^{\circ} \mathrm{C}$. erfolgte, während dies bei den früheren Versuchen in Königsberg nicht unter $35^{\circ} \mathrm{C}$. einzutreten 
pflegte. Doch können auch individuelle oder rasseneigenthümliche Empfänglichkeitsunterschiede der Frösche die Ursache dieser unerheblichen Abweichung sein. Dass jedenfalls virulente, im Frosche ausgewachsene Sporen in demselben auch ohne Leukocyteneinfluss zu Grunde gehen, ist als sicher feststehend zu betrachten, und diese Thatsache allein bietet, wie mir scheint, ein ausschlaggebendes Argument gegen Metschnikoff's Phagocytentheorie.

\section{III.}

Ich komme nun zu Versuchen, welche von Metschnik off als Experimenta crucis bezeichnet worden sind, weil durch dieselben angestrebt wird, den Einfluss der Leukocyten im Frosche zu beseitigen. Metschnik off hat zu diesem Zwecke sporenhaltige Seidenfäden innerhalb von Schilfrohrsäckchen oder in Filtrirpapier gewickelt in den Froschlymphsack eingeführt, während er zur Controlle gleichzeitig sporenhaltige Fäden frei in den Lymphsack that. Er beobachtete nun, dass in demselben Frosche die in der Umhüllung befindlichen Sporen, an welche die Leukocyten nicht herankonnten, auswuchsen, während die ohne Hülle eingeführten Sporen gar kein oder nur sehr spärliches Wachsthum zeigten.

Diese Versuche waren mir zur Zeit meiner ersten Arbeit leider noch nicht bekannt. Ich unternahm jedoch in demselben Bestreben, den Leukocyteneinfluss auszuschalten, die Versuche in der Weise, dass ich Culturbacillen innerhalb wurstartiger Segmente, welche ich aus Froschoder Mäusedarm gewonnen hatte, in den Lymphsack einführte. Die Bacillen schienen, Dank dem mitgegebenen Nährmaterial, ihr Wachsthum zunächst noch fortzusetzen. Am dritten und vierten Tage nach der Einführung jedoch konnte ich ausgedehnte Degeneration langer Bacillenfäden bemerken, diese Degeneration bei vorhandenem Nährmaterial konnte ich nicht anders, als durch Einwirkung einer durch die Darmsegmente hindurchgedrungenen bacillenfeindlichen Substanz deuten. Auch vollständigen Virulenzverlust konnte ich nach vier bis sechs Tagen an dem Inhalt durchlässigerer Darmschlingen constatiren. In letztere waren auch spärliche Leukocyten eingedrungen, hatten aber zu einer kaum in Betracht kommenden Phagocytose geführt, während die überwiegende Mehrzahl der Bacillen in der freien Lymphflüssigkeit zu Grunde gegangen waren. (Darmschlingen, welche eine Oeffnung hatten, sind bei diesen Versuchen nicht in Betracht gezogen, da solche stets dick mit einer gallertigen, viele zerfallene Leukocyten enthaltenden Masse angefüllt gefunden wurden.) Dass in dem benutzten Culturmaterial eine wesentliche Zahl abgestorbener Bacillen sicher nicht vorhanden war, ist bereits unter I hervorgehoben worden. 
Neuerdings habe ich nun die betreffenden Versuche theils mit sporenhaltigen Seidenfäden, theils mit Milzbrandblut wiederholt, welche ich in wie früher präparirten Meerschweinchendarm einschloss. ${ }^{1}$ Ich habe nun in der That die Beobachtung Metschnikoff's, dass unter Umständen ein gleichzeitiges Auswachsen der Sporen in der Hülle bei Wachsthumsausbleib ausserhalb derselben zu erzielen ist, bestätigen können. Während indessen Metschnikoff dieses Resultat bei einer sommerlichen Zimmertemperatur, "welche zwischen 20 und $22^{\circ} \mathrm{C}$. schwankte", erhielt, wuchsen in meinen Versuchen bei der zwischen 16 und $22^{\circ}$ C. schwankenden Temperatur eines geheizten Zimmers die Sporen, wie auch die Blutbacillen weder im freien Lymphsack, noch auch in der Membran. Dieses Resultat ist bei dem benutzten Material leicht mit Sicherheit festzustellen und jedenfalls bemerkenswerth, zumal da die Blutbacillen inmitten eines geeigneten Nährmaterials in das Darmsegment gebracht werden und da auf künstlichen Nährböden die Milzbrand-Bacillen und -Sporen bei den angegebenen Temperaturen recht gut wachsen. Erst bei gelinder künstlicher Erwärmung der Frösche bis anf mindestens $24^{\circ} \mathrm{C}$. erreichte ich ein reichliches Auswachsen der in der Hülle befindlichen Sporen, während die zur Controle in den freien Lymphsack gebrachten Sporen theils gar nicht, theils zu ganz kurzen ovoïden Gebilden auswuchsen, welche übrigens wiederum nicht bloss in Leukocyten, sondern in überwiegender Zahl frei zu finden waren, so dass ein unbefangener Beobachter den Ausbleib weiteren Wachsthums nicht auf die Fresslust der Leukocyten schieben kann. Bei höheren Temperaturen von $26^{\circ} \mathrm{C}$. aufwärts - wuchsen auch die in den freien Lymphsack eingeführten Sporen zu längeren Fäden und gingen in der früher beschriebenen Weise wieder zu Grunde. Durchsuchte man nun aber den Inhalt eines Darmsäckchens, in welchem Sporen innerhalb des Frosches ausgewachsen waren, genauer, so fand man besonders in denjenigen Präparaten, welche durch Auftupfen der Innenwand des Säckchens auf Deckgläser gewonnen waren, welche also die am meisten wandständigen Bacillen zur Anschauung brachten, ausser noch gesund aussehenden Fäden auch viele eigenthümlich veränderte. Schon ein 24 Stunden nach der Beschickung entnommenes Sïckchen enthielt die in Fig. IV wiedergegebenen Bacillen, welche ausser allgemeiner Anschwellung eine eigenthümliche Blasenbildung an den Berührungsstellen der Einzelglieder zeigen. Bei der Färbung mit Methylenblau nimmt nur der Inhalt der Fäden die Fürbung an, während die vielfach deutlich unterscheidbare Hülle, sowie

1 Rollen oder Päckchen von Filtrirpapier, welche Metschuikoff anwendete, machen sehr viel erheblichere Verletzung des Frosches nöthig end zerreissen leicht beim Herausnehmen. 
die blasigen Quellungen ungefärbt bleiben. Bei den später enitnommenen Säckchen finden sich dann vielfach vacuolenartige helle Punkte in den Bacillenfäden, sowie schliesslich auch jene bambusstabähnlichen Degenerationsformen (analog Fig. III). ${ }^{1}$

Gehen wir nun an die Deutung der unter diesem Abschnitt-aufgeführten mannigfachen und anscheinend einander widersprechenden Er' scheinungen, so müssen wir zunächst eine Erklärung suchen für die auffallende Thatsache, dass bei etwa $24^{\circ} \mathrm{C}$. die in den freien Lymphsack eingeführten Sporen nicht auszuwachsen vermögen, während in demselben Frosche die in eine Membran eingeschlossenen recht gut wachsen. Metschnik off schiebt diese Erscheinung gemäss seiner Theorie auf die im freien Lymphsack unbehindert waltende Phagocytose, doch berücksichtigt er auch die Möglichkeit des Einwandes, dass etwaige bacterienfeindliche chemische Substanzen durch jene Membranen nicht hindurchzudringen vermöchten; er ist sich also durchaus bewusst, dass die von ihm beobachtete Erscheinung als beweiskräftiges „Experimentum crucis“ nicht gelten könne.

Nach meinen Beobachtungen erscheint es nun sehr unwahrscheinlich, dass die Leukocyten das wesentliche Hinderniss eines Auswachsens der Sporen im freien lymphsack bilden, da ich (in Uebereinstimmung mit den unter I und II aufgeführten Beobachtungen) oft und regelmüssig constatiren konnte, dass bei Weitem nicht alle eingeführten Sporen, bezw. die daraus hervorgegangenen kurzen Elemente von Leukocyten aufgenommen werden. Dass jedoch andererseits die zu vermuthenden chemisch wirksamen Bestandtheile des Froschkörpers Membranen durchaus nicht zu durchdringen vermöchten, erscheint darum wieder unwahrscheinlich, weil doch wiederholt vielfache Degenerationsformen in den Säckchen vorgefunden wurden, trotz.offenbar vorhandenen genügenden Nährmaterials.

Vielleicht darf zum Verständniss der in Frage stehenden Erscheinung eine Beobachtung von Sirotinin ${ }^{1}$ unter Flügge herangezogen werden, dass nämlich bei der Filtration ptomaïnhaltiger Substanzen (durch Thoncylinder) zuerst eine ptomaïnfreie Flüssigkeit hindurch filtrirt und erst später die Ptomaïne selbst. Analog könnte man nun die in Frage stehenden Erscheinungen im Frosche ohne Metschnik off's Theorie so erklären, dass durch die angewandten Umbüllungen der Sporen zunächst nur ein dünnes Serum hindurchfiltrirt, welches nur dem Bacillenwachsthum günstige Bestandtheile - deren unzweifelhaft auch im Frosche vorhanden sind - enthält, and dass später erst (etwa gegen Ende des ersten Tages) auch die bacillenfeindlichen Bestandtheile hindurchzudringen vermögen.

1 Siehe Anmerkung zu den Abbildungen.

2 Diese Zeitschrift. Bd. IV. S. 219 und Bd.V. 
Einwirkungen D. Lebend. F'roschikörpers A. D. Mimzdrandiaciluus. 83

IV.

Welcher Art nun die zu vermuthenden bacillenfeindlichen Bestandtheile des Froschkürpers seien, dafür konnte bisher ein positiver Auhalt nicht gewonnen werden; nur so viel ging schon aus den früheren Untersuchungen hervor, dass die Wirksamkeit derselben keine sehr grosse sei, da dieselbe-bei relativ geringer Temperatur die eingeführten Bacillen, bezw. junge Sporenkeimlinge zwar schädigen konnte, aber bei Brüttemperatur der vermehrten Wachsthumsenergie der Milzbrandbacillen (im Gegensatz zur Warmblüter-Immunität) nicht Einhalt zu thun vermochte.

Nachdem nun C. Fränkel ${ }^{1}$ die milzbrandfeindliche Wirkung der Kohlensäure nachgewiesen hatte und Behring ${ }^{2}$ den auffallenden Einfluss derselben auf Nährsubstrate, namentlich Blutserum, fand, lag es nahe, eine so eng mit der Lebensthätigkeit des Thierkörpers verknüpfte Substanz auch mit den Schicksalen der Milzbrandbacillen im Frosche in Zusammenhang zu bringen; namentlich da ron den bisher beobachteten Erscheinungen keine einzige gegen einen derartigen Zusammenhang spricht, manche Thatsachen vielmehr sogar durch einen solchen dem theoretischen Verständniss näher gerückt werden würden. Der Umstand z. B., dass im hüngenden Tropfen ans Froschlymphe die Milzbrandbacillen gut gedeihen, innerhalb des Froschkörpers aber nicht, liesse sich sehr wohl so deuten, dass die im Lymphtropfen vorhandene geringe Kohlensäuremenge (welche durch die Präparation vielleicht noch zum Theil ausgetrieben wird) leicht durch die nach Behring ${ }^{3}$ sauren - Stoffwechselproducte des Milabrandbacillus vertrieben oder wenigstens ihr Einfluss überwunden werden kann, während innerhalb des lebenden Froschkörpers immer neue Kohlensäuremengen gebildet werden. In gleicher Weise würde auch die Bacillenwucherung im erwärmten Frosch verständlicher sein, wenn man bedenkt, dass durch die Wärme die in Flüssigkeiten gelöste Kohlensäure eine Verminderung; die Wachsthumsenergie der Bacillen aber einen bedeutenden Zuwachs erfährt. Auch die Versuche mit den Darmsäckehen u.s. w. würden der gedachten Annahme nicht widerstreiten, da bekanntermassen Gase auch durch Membranen hindurch wirken, aber natürlich in langsamerer Weise, als bei unbehindertem Flüssigkeitsaustausch.

Dass im Frosche wie in jedem anderen Thierkörper Kohlensäure durch den Lebensprocess gebildet wird und bis zu einem gewissen Concentrationsgrade in den Körperflüssigkeiten - nicht blos im Hämoglobin der rothen

1 Diese Zeitsclirift. Bu. V.

2 Behring, Beiträge zur Aetiologie des Milzbrandes. Diese Zeitschrift. Bd. VI. S. 117. 
Blutkörper - vorhanden ist, unterliegt wohl keinem Zweifel. Ob indessen diese Kohlensäuremenge einen wesentlichen Einfluss auf die eingeführten Milzbrandbacillen ausübt, schien am besten dadurch feststellbar zu sein, dass man versucht, die im Froschkörper vorhandene Kohlensäure pach Möglichkeit zu eliminiren und dann den Einfluss dieser Abänderung auf eingeführte Bacillen oder Sporen zu beobachten. Die Herabsetzung der Kohlensüure kann nun aber auf zwei verschiedene Arten angestrebt werden, indem man sie entweder durch stärkere Säuren auszutreiben oder durch Alkalien zu binden sucht. Diese Aufgabe ist in beiden Fällen nicht so leicht, da die andauernde Kohlensäurebildung ja auf's Engste von der Lebensthätigkeit aller Körpergewebe abhängt und durch kleinere Dosen von Chemikalien kaum beeinflusst werden dürfte, während grössere Mengen von Säuren oder Alkalien eine $z u$ intensive Schädigung des Versuchsthieres bedingen würden. Vor Allem schien, es schwer, einen permanent wirkenden und auch nur annähernd gleichmässig die Kohlensäuremenge in den Körperflüssigkeiten herabsetzenden Einfluss herzustellen. - Von den vorläufigen Versuchen, welche ich in dieser Richtung anstellte und welche aus äusseren Gründen unterbrochen wurden, will ich nur mittheilen, dass ich in Fröschen, welche mit Milchsäurebacillen vorgeimpft waren, sowie in solchen, welche mit Barythydrat behandelt wurden, das Auswachsen von Milzbrandsporen anch bei Zimmertemperatur beobachtet habe. In den Barytfröschen trat dies Resultat sogar von einem Nachmittag bis zum anderen Morgen, also während der kühlsten Zeit des Tages, in vier Versuchen mit Regelmüssigkeit ein. Die Sporen wuchsen allerdings nur zu ziemlich kurzen Fäden aus, welche verkümmert aussahen und keine Neigung zum Weiterwachsen zeigten. Da diese Versuche ihren Abschluss noch nicht gefunden haben, möchte ich es vermeiden, dieselben $\mathrm{zu}$ strengeren Argumentationen zu verwerthen. Meine subjective Ueberzeugung aber neigt sich schon nach diesen vorläufigen Resultaten der Annahme zu, dass bei der Behinderung des Sporenwachsthums im Froschkörper bei Zimmertemperatur die Kohlensäure in der That eine Rolle spiele. $\mathrm{Ob}$ die Kohlensäure indessen das einzige im Frosche wirksame Moment sei, bezw. welchen Antheil sie an den beobachteten Erscheinungen habe, will ich durchaus dahingestellt sein lassen. Es wird dies durch weitere Versuche festzustellen sein. Ueberdies ist mir wohl bewusst, dass Metschnik off ron seiner Theorie aus bei allen chemischen Eingriffen in den Thierkörper eine Schädigung oder Lähmung der Leukocyten annehmen und die Erscheinungen hieraus zu erklären suchen kann. Darum schien es mir am wichtigsten, zunächst möglichst genau nachzuweisen. warum Metschnikoff's. Theoric für die Erklärung der Erscheinungen im Milzbrandfrosche unzureichend sei. 
Einwirkungen D. Lebend. Froschiörpers a. D. MULzbrandbaClluus. 85

\section{Erklärung der Abbildungen.}

\section{(Taf. I.)}

Fig. I und II stammen von den früheren Versuchen mit sporenrcichen Kartoffeleulturen, welche zwei Stunden lang auf $62^{\circ}$. C. erhitzt wurden, um die Sporen $\mathrm{zu}$ isoliren.

Fig. I stellt Milzbrandfäden dar, welche aus diesen Sporen bei einer zwischen 35 und $37^{\circ} \mathrm{C}$. sich bewegenden Brütschranktemperatur (unter I uftzufuhr von iussen) im Froschlymphsack ausgewachsen sind und unter Uebergang in's Blut und die Organe den Tod des Frosches bewirkt hatten. (Färbung nach Gram.)

Fig. II ist durch Auswachsen derselben Sporen bei einer nur um $7^{\circ} \mathrm{C}$. geringeren T'emperatur ( 28 bis $30^{\circ} \mathrm{C}$.) entstanden und zeigt Degeneration eines längeren, schlingenförmigen Fadens ohne Phagocytose. (Das Präparat ist mit Bismarckbraun [Vesuvin] gefärbt.) Der Unterschied von Fig. I. ist bei gleichzeitiger Betrachtung beider Bilder besonders augenfällig.

Fig. III und IV stammen aus Präparaten, welche im hygienischen Institut zu Berlin gewonnen worden.

Fig. III zeigt einen aus dem Blute einer Milzbrandmans stammenden und unter dem Einfluss der Ofenwärme im Frosehe etwas ausgewachsenen Bacillenfaden, welwher bei 1000 facher Vergrösserung die Details der eingetretenen Degeneration erkennen lässt. (Färbung mit Methylenblau.)

Fig. IV stellt ein Präparat dar, welches aus den Inhalt eines mit cinem Sporenfaden besehickten und im Froschkörper 24 Stunden bei 28 bis $30^{\circ} \mathrm{C}$. verbliebenen Darmsegments gewonnen ist. Der kïrzere und dickere Bacillenfaden zeigt eine ge"quollene, durchscheinende Hälle und blasige Auftreibungen an den Enden der Einzelylieder. Letztere Erscheinung zeigt sich an dem dünneren und längeren Faden im Beginn begriffen.

1 Durch Beobachtung einer grösseren Anzahl von Präparaten bin ich zu der Ueberzeugung gelangt, duss diese Aufteibungen den Beginn der Degeneration, die in Fig. III dargestellte Gestaltveränderung schon den Fort-chritt derselben kennzeichnet.

(Alle wiedergegebenen Präiparate sind ohne Erhitzen der Deckglïser gewonnen worlen.) 